\title{
Study on the Cultural Connotation of Tibetan Music
}

\author{
Shuyue Ding ${ }^{1, *}$ \\ ${ }^{1}$ Mianyang Teacher's College, Mianyang, Sichuan, China \\ "Corresponding author.Email:2248363@qq.com

\begin{abstract}
Amid the traditional Chinese culture, a major component is the music culture, which occupies a very important position. And amid the Chinese music culture, Tibetan music culture forms a main composition. This paper summarizes the classification of Tibetan music, makes an analysis and expounds on the cultural characteristics and cultural connotation of Tibetan music. It also puts forward some suggestions on how to develop Tibetan cultural resources and the creation of modern Tibetan music.
\end{abstract}

\section{Keywords: Tibetan music culture, traditional culture, cultural deposits}

\section{INTRODUCTION}

China has many different ethnic groups with their different cultural characteristics, which can be reflected in the costumes, languages, customs and other aspects. The Tibetan region has its own unique traditional music culture, and folk music is the main component of Tibetan music. In the Tibetan music, the living atmosphere of this ethnic group can be displayed, and the connotation of music with a mysterious ethnic color can be reflected.

\section{THE ClassifiCATION OF TIBETAN MUSIC}

In China, the Tibetans are a minority nationality with a long history of development. Due to the unique geographical location and environment, the Tibetan nationality has a very obvious regionalism. Moreover, this ethnic group has its own unique cultural content, which is closely related to the daily life of the Tibetan people. The music content shows People's Daily life and emotions.

\section{A. Tibetan folk music}

The Tibetan people have a great deal of folk music, with a wide variety of musical forms and contents. In the daily life of Tibetan people, Tibetan music culture is embodied in various aspects, such as ethnic music, music for learning and folk songs. As a kind of folk music often sang by Tibetan people, the folk song has a wide vocal range and a large singing space. Its rhythm is relatively cheerful and the tone is high and low, which makes one excited and stimulated in the process of singing. In their life, the Tibetan people always do some farm work, in which process they express their passion for work by singing. Tibetan people would sing aloud when grazing, usually in the organic combination of labor activities and music rhythm they constantly improve their efficiency of labor. This type of music is relatively cheerful, with a distinct rhythm and pulse. When expressing their feelings to the people they love, the Tibetan people also use music to express their feelings. This kind of song has a lot of emotion, relatively free content, with different rhythms.

Tibetan music, as an artistic culture, deeply shows people's daily life and local customs, and is of very high value of art appreciation. Seen from the geographical location, the Tibetan area has a relatively harsh living environment. Not afraid of difficulties and obstacles, the Tibetan people growing up here have created a nomadic culture which is prosperous and lead a free life. This culture contributes to high achievements of the nationality. In the Tibetan music culture, the creators can integrate people's daily life, their imagination and the scenery in their music. Whether it is the vast grassland or the cattle and sheep of the tribe, it can be expressed in the music. It can be said that the Tibetan folk music has been integrated into the daily life of the people, closely connecting the two. Each piece of music shows the rich daily life of the local people, expresses the feelings of the Tibetan people, enriches their spiritual world, and reflects the life attitude and work culture of them.

\section{B. The Tibetan religious music}

The music culture in the Tibetan area was closely connected with the religious culture at the very beginning. Since Buddhism was introduced into the region in the seventh century, the culture of Tibet has become inseparable from Buddhism, and religious and cultural beliefs with Tibetan national characteristics emerged. Many legends of Tibet show that the local people have rich romantic feelings and rich spiritual world. Tibetan Buddhism has influenced people's thoughts, behaviors and life orientation to some extent. Humanistic care is fully conveyed in the lyrics, which 
expresses the coordination of people's natural life and shows the optimistic attitude of the people in Tibet. With the continuous development of the society and the constant changes of the times, the rhythm of people's life is becoming faster and faster. Troubled by different life trifles, people fully express their expectations for a better life in folk music, which has a profound meaning. In the process of creating Tibetan religious music, the focus is Buddhism and temples, and the characteristics of folk music are also integrated into the ethnic music. Some religious instruments, such as the suona and so on, are used in this music, and sutras are also incorporated into it, performed in some special festivals or rituals. For example, in some Tibetan monasteries, Buddhist festivals and other festivals, this musical art form is performed. Among these festivals, the performance of this musical art form occupies a very high position, which can perfectly display the ideological characteristics and values of the Tibetan people.

\section{CUltural Characteristics OF TIBETAN MUSIC}

\section{A. The influence of Tibetan folk customs on music culture}

In general, the artistic expression of ethnic minorities has a strong ethnic color, and the same is true of Tibetan music. People living in Tibetan areas, whether they are men, women or children, old or young, can sing and dance. Compared with other ethnic groups, the Tibetan music has more outstanding changes in content and rich forms, and embodies the strong national color in all aspects. This is why Tibetan music attracts people and keeps them exploring it. Besides, Tibetan music can also reflect people's daily living habits and folk customs. Young Tibetan people apply music in their expression of feelings so as to make others feel their sincerity. In some traditional Tibetan festivals, people also sing and dance to celebrate the festival and wish their family and friends well. These songs reflect the simple spiritual quality of Tibetan people and express their yearning for a better life.

\section{B. The effect of rich natural landscape on music culture}

The Tibetan area is relatively unique, with many natural wonders, including lakes, forests, river valleys and grasslands. People enjoy the natural beauty of the mountains and rivers. In many Tibetan music works, the natural landscape of these areas are depicted, showing a beautiful picture of nature to people. For example, the song "Qinghai-Tibet Plateau" presents the quiet and beautiful natural scenery of Tibet to people. The description of these scenes in the song seems to bring people into the unique place of Tibet and let people feel the scenery and wander in the song.

\section{The influence of their life attitude on songs}

Due to the influence of living environment, Tibetan people have different characteristics in their attitude towards life. Many Tibetan people are hard-working, brave, hospitable and eager for a harmonious and happy family life. The banquets of the Tibetan people and their hada can reflect their psychological state of praying for a better life and the humanistic feelings of the Tibetan people contained in music. Therefore, whenever sung, the Tibetan music can express the beautiful and joyful feelings. In whatever life atmosphere, the traditional Tibetan folk music can show their sincere blessing in the song. The Tibetan people provide people with different musical feelings and accumulate a strong spiritual culture among the people, showing their profound psychology of blessing and blessing.

\section{Special religious festivals}

In the Tibetan festivals, there are rich and unique Tibetan song and dance types with rich music. For many local festivals, the organizers are religious institutions and involve a wide range of categories. Generally speaking, religious festivals can be divided into three categories: one is the religious festivals held by the temple in fixed days of festivals, such as the Lamp Festival, Prayers' Ceremony and Sho Dun Festival; the second is the folk spontaneous religious festivals, specific festivals such as Worship Snow Mountain in Qinghai region, etc.; the third is the festivals inherited from primitive beliefs and myths, such as the Mani Festival and the Zhachong Festival in Sichuan. Different religious festivals have their own religious music, and different music has its own important role. They can play the role of character molding and self-cultivation.

\section{THE CULTURAL CONNOTATION OF TIBETAN MUSIC}

Influenced by its own national characteristics, the Tibetan music highlights its own profound and unique cultural connotation. In this chapter, the cultural connotation of Tibetan music is to be analyzed.

\section{A. Simple folk customs}

The Tibetan nation has a long history of social life. With the cultural accumulation of the Tibetan nation, profound folk customs and cultural deposits also come into being. Among the profound folk customs and cultural background, the content with profound influence, characteristics and representativeness is the Tibetan dance and song. In the vast Tibetan territory, songs of wine, nursery rhymes and folk songs are 
indispensable to the daily life of the Tibetan people. Tibetans of all kinds are generally good at singing and dancing. From the above facts, it can be seen that Tibetan music is profound and of primitive simplicity. Compared with other ethnic songs and dances, Tibetan songs and dances have unique and outstanding characteristics, such as their own rhythm and melody, and there are featured dances such as string dance and tap dance. In the process of the emergence and continuous development of Tibetan music, it has also formed its own profound charm and advantages, which are just welcomed by people in other regions. In the Tibetan cultural traditions such as marriage custom, lodging, etc., the connotation of Tibetan music is also reflected to some extent. For example, in the traditional festival of Tibetan New Year and Sho Dun Festival, people often gather to sing and dance. Tibetan young women meet and fall in love with each other in the youth song festival, which cannot do without songs, dances and other music forms. Therefore, it can be seen that Tibetan music is an important part of the Tibetan people and an indispensable part of their daily life, playing an important role in different aspects. In the process of actual development of Tibetan music, the relevant creators also need to combine with the characteristics of the times and specific conditions to effectively make innovations in different aspects of Tibetan music.

\section{B. Rich natural landscape}

Tibetan music is also full of praise for the natural scenery, such as the songs "Qinghai-Tibet Plateau", "Magic of Jiuzhaigou", etc., which contain the Tibetan people's reverence for the natural landscape and love for the great rivers and mountains. Tibetan people's love for mountains and rivers is related to the regional environment they are in. As is known to all, the Tibetan region has a very wide geographical area, as well as the rich and diverse, unique natural landforms and landscapes, which contain a variety of landscape types, such as lakes, valleys, rivers, plateaus, forests and grasslands. The magnificent landscape also makes people feel sacred, so there are songs about natural landscape in Tibetan music. Through these rich songs of natural landscape, people can feel the magnificent beauty of great rivers and mountains, and feel the boundary of blending human and natural landscape. In addition, combined with the natural voice of Tibetan people, Tibetan music is pure and shocking.

\section{Profound and unique historical and cultural background}

There is also a close relationship between Tibetan music and the politics, culture and economy of the times. Living on the Qinghai-Tibet Plateau, the Tibetan people have, with their diligence and wisdom, promoted the emergence of a unique and profound spiritual and material culture. Influenced by the unique Tibetan culture, scholars have been strengthening the research on Tibetan culture. For musicians, Tibetan music is one of their favorites. Whenever in the adaptation of folk songs, or the collection of music, one can feel the long and profound national culture behind them. More and more people are attracted by Tibetan music and experience the charm of Tibetan culture through Tibetan music to improve their spiritual experience.

\section{Auspicious blessings}

The production and living environment in Tibetan areas is relatively poor, so the Tibetan people living there have to make long-time struggle with nature. Under such natural conditions, the Tibetan people can still enjoy a happy life and hope for the best. Therefore, influenced by the above psychology of Tibetan people, Tibetan music also conveys auspicious blessings to a certain extent. In Tibetan culture, many things can reflect the musical charm and cultural connotation of Tibetan culture, such as wine, hada, wishes and so on. Through these beautiful things, the elements showing the simplicity of Tibetan music make people yearn for a more simple life and environment. It is because of the above factors that more and more people get to like Tibetan music. Tibetan music also infuses the vitality of the new era on the basis of traditional culture to promote its continuous development.

\section{DEVELOPING TiBETAN CULTURAL RESOURCES}

In the development of Tibetan music cultural resources, the main contents excavated by relevant personnel is the Tibetan music art, and most of the works created are dominated by Tibetan music elements. When creating works through combining with Tibetan music, some musicians will increase the absorption of foreign advanced elements, and integrate Tibetan music to create new works. For the current development of Tibetan music, it is still based on Tibetan characteristics and still uses traditional Tibetan music melody and rhythm. On the other hand, the Tibetan culture in the new era is no longer limited to the single Tibetan language and applied different languages, which promoted the expansion of the popularity of Tibetan music.

In the process of creation, modern Tibetan music is still based on the traditional Tibetan culture, involving a large number of contents and types, and also contains its own unique religious color with a variety of songs. At the same time, as more and more people pay attention to Tibetan songs with the development of society, the interpretation of Tibetan songs is more flexible and can effectively combine the characteristics of the times and the nation. At the same time, it can also 
absorb some foreign elements and add modern elements in the development process, which promotes the development of more abundant Tibetan songs. In the development of Tibetan rock songs, the creators apply new musical techniques and adapt them to new musical expression and new instruments, so as to promote a more comprehensive display of Tibetan music and enhance its spread. In the development of Tibetan music, electronic music can also be used to show the unique charm of Tibetan music, improve the musicality and artistry of Tibetan music, so that Tibetan music can be more accessible to the general public. Meanwhile, in the development of modern Tibetan music, its speed and quality are getting higher and higher. Compared with other music, Tibetan music has been developed later and faster, and the quality of Tibetan music creation is getting higher and higher. Living in a relatively vast area with a complex climate where people in different regions use different languages, the local Tibetan people gradually form their own unique Tibetan music style with the geography and human factors.

\section{CONCLUSION}

To sum up, this paper discusses the four aspects of Tibetan music. Tibetan music plays an important role in the daily life of the Tibetan people. With the development of The Times, Tibetan music has been known by more and more people and brought more people beautiful experience. In the development of modern Tibetan music, the composer should also combine with the actual situation of different aspects to improve its further development.

\section{References}

[1] Miu Hange. Analysis of Tibetan Musical Elements in "A Sketch of Tibet" (1) [J]. Song of the Yellow River, 2017, (11): 84-85. (in Chinese)

[2] Zhong Lei. Opinion on the Development of Tibetan Music in Ganzi Prefecture from the Perspective of the Integration of Tibetan and Han Cultures [J]. Encyclopedia Form, 2019, (4): 759. (in Chinese)

[3] Ma Weina. Research on Tibetan Musical Cultural Characteristics and Ethnic Exchanges [J]. Northern Music, 2017, 37 (11): 40-41, 47. (in Chinese)

[4] Losang Khedrub. The Development and Characteristics of Tibetan Folk Music [J]. Tibet Studies, 2016(01):38-44. (in Chinese)

[5] Tian Liantao. A Study on Tibetan Batang Xianzi Music [J]. Chinese Music, 2012(01): 46-48. (in Chinese)

[6] Chen Zhong. Analysis and thinking on the current status of the study of Tibetan music history [J]. Tibetan Art Studies, 2008(01):49-56. (in Chinese) 